\section{Comparison of vision- related quality of life in primary open-angle glaucoma and dry-type age-related macular degeneration}

S Karadeniz Ugurlu, AE Kocakaya Altundal and

M Altin Ekin

\begin{abstract}
Purpose To compare quality of life (QoL) in patients with primary open-angle glaucoma (POAG) and dry-type age-related macular degeneration (AMD) with similar bestcorrected visual acuity.

Methods Age-, sex-, and visual acuitymatched POAG and dry AMD patients were included in the study. Each patient performed 24-2 and 10-2 SITA standard visual field tests. Contrast sensitivity was evaluated with CSV-1000 HGT instrument. The 25 item National Eye Institute Visual Function Questionnaire (NEI-VFQ-25) was used to analyze QoL. Overall and subscale scores were converted to scores between 0 and 100, the higher scores indicating better visionrelated QoL.

Results Overall NEI-VFQ-25 scores were 86.44 and 84.66 in glaucoma and AMD groups, respectively $(P=0.244)$. The highest scores were obtained in 'vision-related dependency' subgroup in glaucoma and 'color and peripheral vision' in AMD group, whereas the lowest scores were noted 'in peripheral vision' in both glaucoma and AMD patients. Glaucoma patients had significantly lower scores in ocular pain, color vision, and peripheral vision subgroups compared with the AMD group, whereas AMD patients had lower scores in near and distance vision activities, vision-related social activity, and dependency subgroups. Contrast sensitivity results and mean defect values showed correlation with NEI-VFQ-25 scores in both groups.

Conclusions Glaucoma and AMD patients with similar visual acuity experienced similar overall impairment in QoL. However, glaucoma patients described more difficulty with peripheral vision and ocular pain,
\end{abstract}

whereas AMD patients complained more about near and distance vision and dependency items. Eye (2017) 31, 395-405; doi:10.1038/eye.2016.219; published online 4 November 2016

Introduction

Glaucoma and age-related macular degeneration (AMD) are the leading causes of poor visionspecific functioning and irreversible blindness in adults 40 years and older. ${ }^{1-4}$ It is expected that the prevalence of glaucoma, AMD, and blindness associated with them will increase markedly as the population ages. ${ }^{5}$ Despite the fact that glaucoma and AMD mainly affect peripheral and central vision, respectively, these patients share significant reduction in quality of life (QoL), and have a higher likelihood of suffering from anxiety-related disorders and depression. ${ }^{4,6-8}$

To estimate the effect of a disease on patients' life and measure the success of treatment strategies, specific instruments apart from ophthalmic examinations are needed. Over the past two decades, a number of questionnaires measuring the outcomes related to QoL have been developed for patients with visual impairment. ${ }^{9-13}$ The 25 item National Eye Institute Visual Function Questionnaire (NEI-VFQ-25) is an instrument that can be used to assess vision-specific QoL. ${ }^{13}$ It is a shorter, valid, and reliable version of the 51 item NEIVFQ, which has been translated into many languages. Prior studies investigating visionspecific QoL in AMD and glaucoma patients indicated poor outcome. The QoL scores obtained with NEI-VFQ-25 ranged between $69.8 \pm 1.9$ and $90.7 \pm 8.1$ for glaucoma patients and between $51.8 \pm 2.0$ and 79.4 in AMD
Department of

Ophthalmology, Izmir Katip Celebi University Ataturk Teaching and Research Hospital, Izmir, Turkey

\section{Correspondence:}

S Karadeniz Ugurlu, Department of Ophthalmology, Izmir Katip Celebi University Ataturk Teaching and Research Hospital, Izmir 35170, Turkey

Tel: +90 532715 6173; Fax: +90 2322431530 . E-mail: ugurluseyda@yahoo. com

Received: 16 February 2016 Accepted in revised form:

17 August 2016

Published online:

4 November 2016

The study was presented in part at EGS Congress, Nice, 2014. 
patients. ${ }^{4,14-21}$ These studies were mainly conducted in advanced forms of these diseases. ${ }^{4,14-18}$ There is little information about vision-specific QoL among patients with early stages of glaucoma and AMD. ${ }^{19-21}$ There is even less information about the QoL of comparable groups of glaucoma and primary open-angle glaucoma (POAG) patients, and the impact of involvement of different sites, that is, peripheral visual field vs central retina on QoL. The influence of visual disability to perform activities of daily living was generally assessed by tests that evaluated visual acuity and visual field sensitivity. ${ }^{4,15,16,20,22}$ It is also likely that additional tools such as contrast sensitivity (CS) examination could result in better assessment of quality of vision.

The current study was conducted to determine the relationship between QoL and clinical measures including visual acuity, visual field sensitivity, and CS in patients with POAG and AMD with similar best-corrected visual acuity (BCVA) by using the NEI-VFQ-25.

\section{Materials and methods}

The study included 92 consecutive patients who attended Izmir Ataturk Training and Research Hospital with the diagnosis of POAG and early AMD. Participants who had BCVA of 0.1 or more, were either pseudophakic or had less than or equal to grade 1 nuclear sclerosis, and were able to read and answer the questionnaire were included in the study. The patients with the following concomitant conditions were excluded: patients with proliferative and nonproliferative diabetic retinopathy, diabetic macular edema, diseases of optic nerve other than glaucoma, corneal opacity, keratoconus, uveitis, nuclear or cortical cataract greater than grade 1, prior history of ophthalmic surgery within 3 months, dry eye syndrome (Schirmer test $\leq 5 \mathrm{~mm}$ ), and neurological disorders such as dementia or mental retardation. This study was completed in accordance with the Declaration of Helsinki (2008). Ethical approval was granted and informed consent was obtained from all patients. POAG was diagnosed in patients with high intraocular pressure $(>21 \mathrm{~mm} \mathrm{Hg}$ ), typical optic disc features, and visual field test results along with open angles on gonioscopy. Glaucoma patients were classified to have early, moderate, or severe disease according to the European Glaucoma Society classification guidelines (Hodapp-Anderson-Parish classification scheme) based on mean defect (MD) value of the eye with better BCVA. ${ }^{23,24}$ Early AMD was defined as the presence of one or more large $(>63 \mu \mathrm{m})$ druse and focal hyperpigmentation, and/or hypopigmentation of the retinal pigment epithelium. ${ }^{25}$

The patients underwent complete ophthalmic examination including evaluation of the anterior and posterior segment, measurement of intraocular pressure, gonioscopy, and assessment of visual acuity, visual field, and CS. In a given patient, the eye with better BCVA was included in the analysis. One of the eyes was randomly chosen for the analysis when both eyes had same BCVA. The 24-2 and 10-2 SITA visual field tests were performed on the Humphrey Visual Field Analyzer (Model 750i, Humphrey Instruments Inc., San Leandro, CA, USA). Each subject viewed targets through his/her best correction for the test distance. Visual field defect was defined as a cluster of two abnormal points at $P<0.5 \%$ or three abnormal points at $P<1 \%$ in $24-2$ SITA test. The number of visual field defects extending into central $10^{\circ}$ was documented. Contrast sensitivities of the patients were measured by CSV-1000 HGT (Vector, Vision, Greenville, OH, USA) monocularly under photopic conditions $\left(85 \mathrm{~cd} / \mathrm{m}^{2}\right)$ at a distance of $2.5 \mathrm{~m}$. The CSV-1000 test provided CS at four spatial frequencies ( $A=3$ c.p.d., $B=6$ c.p.d., $C=12$ c.p.d., and $D=18$ c.p.d.). The results were used to form CS curve and were converted to the logarithmic scale. ${ }^{26}$

Vision-specific QoL was evaluated by the Turkish version of the NEI-VFQ-25, ${ }^{27}$ which was designed to measure the level of severity of particular visual symptoms or difficulty of activities on 12 generic health domains: general health, general vision, ocular pain, near activities, distance activities, vision-specific social functioning, vision-specific mental health, vision-specific role difficulties, vision-specific dependency, driving, color vision, and peripheral vision. The total score ranged from 0 to 100 , with higher scores indicating better visual functioning and well-being. The parameter regarding driving difficulties was excluded from the questionnaire; there was only one patient in the study group who had a driving licence and was driving his car on a regular basis. Hence, 11 of the 12 subgroup scores were averaged to yield a composite score.

Statistical analysis was performed using SPSS (Statistical Package for the Social Sciences for Windows version 17.0, SPSS Inc., Chicago, IL, USA). Continuous data were presented as mean $\pm \mathrm{SD}$, whereas categorical data were presented as number of patients. Independent samples $t$-test was used for normally distributed continuous variables and $\chi^{2}$-test was used for categorical variables. Relative risks with $95 \%$ confidence intervals (CIs) were calculated. A $P$-value $<0.05$ was considered to indicate statistical significance.

\section{Results}

Forty-three patients with POAG and 49 patients with AMD were included in the study. A flowchart is presented to show the patient participation characteristics (Figure 1). Clinical characteristics of the study population were presented in Table 1. Mean ages of patients with 
POAG and AMD were 64.9 \pm 10.5 (range; 50-88) and $67.5 \pm 8.1$ (range; $51-81$ ) years, respectively $(P=0.183)$.

There was no statistically significant difference between the BCVAs of the groups of POAG and AMD (Snellen chart: $0.66 \pm 0.12$ and $0.60 \pm 0.18$, respectively; $P=0.053$ ). Majority of the POAG patients were in the early glaucoma

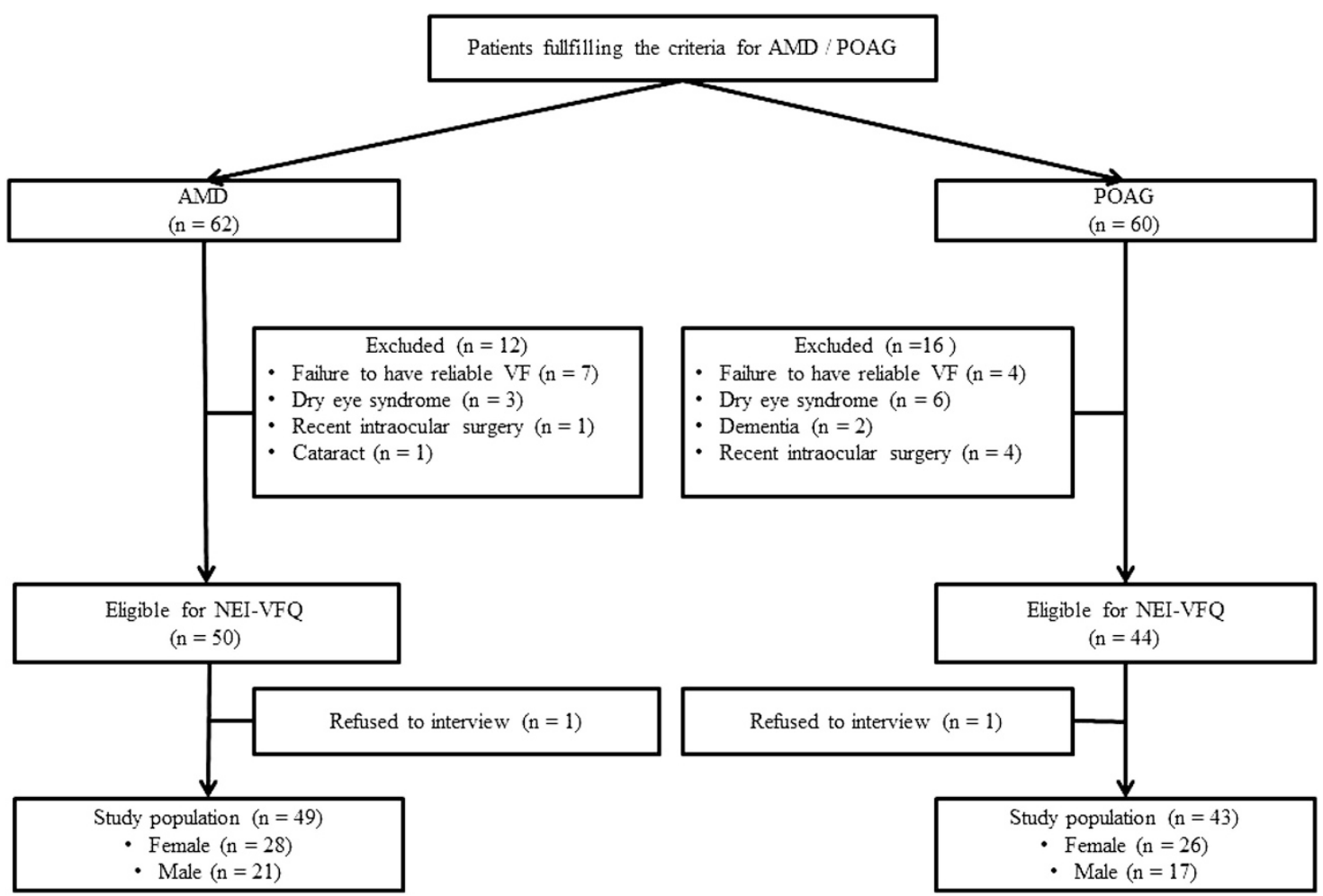

Figure 1 Flowchart illustrating the inclusion/exclusion of individuals in the study. AMD, age-related macular degeneration; POAG, primary open-angle glaucoma.

Table 1 Demographic data, contrast sensitivity values, and visual field test results of the patients with POAG and AMD

\begin{tabular}{|c|c|c|c|}
\hline & $P O A G \mathrm{n}=43$ & $A M D \mathrm{n}=49$ & $\mathrm{P}$ \\
\hline Age (years) & $64.88 \pm 10.52$ & $67.48 \pm 8.10$ & 0.183 \\
\hline $\begin{array}{l}\text { Gender } \\
\quad \text { Female } \\
\text { Male }\end{array}$ & $\begin{array}{c}0.747 \\
26(60.5) \\
17(39.5)\end{array}$ & $\begin{array}{l}28(57.1) \\
21(42.9)\end{array}$ & \\
\hline BCVA (Snellen) & $0.66 \pm 0.12$ & $0.60 \pm 0.18$ & 0.053 \\
\hline $\begin{array}{l}\text { Contrast sensitivity } \\
\text { A } \\
\text { B } \\
\text { C } \\
\text { D }\end{array}$ & $\begin{array}{l}1.40 \pm 0.11 \\
1.61 \pm 0.11 \\
1.31 \pm 0.11 \\
0.71 \pm 0.12\end{array}$ & $\begin{array}{c}1.53 \pm 0.95 \\
1.74 \pm 0.101 \\
1.29 \pm 0.168 \\
0.67 \pm 0.13\end{array}$ & $\begin{array}{c}0.001^{*} \\
0.001^{*} \\
0.775 \\
0.201\end{array}$ \\
\hline $\begin{array}{l}\text { Visual field paramet } \\
\text { 24-2 MD } \\
\text { 24-2 PSD } \\
\text { 10-2 MD } \\
\text { 10-2 PSD }\end{array}$ & $\begin{array}{c}-4.94 \pm 3.45 \\
4.90 \pm 2.34 \\
-0.74 \pm 1.26 \\
1.35 \pm 0.72\end{array}$ & $\begin{array}{c}-1.63 \pm 1.20 \\
1.87 \pm 0.84 \\
-2.85 \pm 1.44 \\
2.51 \pm 1.25\end{array}$ & $\begin{array}{l}0.001^{*} \\
0.001^{*} \\
0.001^{*} \\
0.001^{*}\end{array}$ \\
\hline Central scotoma $^{a}$ & $4(7.7 \%)$ & $18(36.7 \%)$ & $0.002^{*}$ \\
\hline
\end{tabular}

Abbreviations: AMD, age-related macular degeneration; BCVA, best-corrected visual acuity; MD, mean deviation; POAG, primary open-angle glaucoma; PSD, pattern SD. ${ }^{a}$ Number of patients with scotoma extending into central $10^{\circ}$ of $24-2$ standard visual field.

Data are presented as $n(\%)$ or mean $\pm \mathrm{SD} ;{ }^{*} P<0.05$. 
group $(n=37,86 \%)$, and few were in moderate $(n=3,7 \%)$ and advanced groups $(n=3,7 \%)$. AMD group was composed of only early-stage AMD. Comparison of CS of the patients with POAG and AMD revealed similar results except for two spatial frequencies (3 and 6 c.p.d.) where POAG patients were found to have significantly lower levels than those of AMD patients $(P=0.001$;

Table 1). Average MD and PSD values of Humphrey 24-2 SITA and 10-2 SITA visual field tests were presented in Table 1. Scotoma within central $10^{\circ}$ of Humphrey 24-2 standard visual field was identified in $7.7 \%(n=4)$ and $36.7 \%(n=18)$ of POAG and AMD groups, respectively $(P=0.002 ;$ Table 1$)$.

Average subgroup and overall scores of NEI-VFQ-25 test of the POAG and AMD patients were presented in Table 2 and Figure 2. Overall scores of NEI-VFQ-25 were $86.44 \pm 6.96$ and $84.66 \pm 7.56$ for POAG and AMD groups, respectively $(P=0.244)$. Highest mean score of NEI-
VFQ-25 subgroups for patients with POAG was observed in the subgroup of vision-specific dependency

$(96.31 \pm 6.58)$ and lowest mean score was observed in the subgroup of general vision $(60.47 \pm 12.48)$. Highest mean score for AMD group was observed in the subgroups of color and peripheral vision $(100.0 \pm 0.0)$ and lowest score was in general vision $(60.71 \pm 16.92)$. Statistically significant difference was found between the groups of POAG and AMD in subgroups of ocular pain, near activities, distance activities, vision-specific social functioning, vision-specific dependency, color vision, and peripheral vision.

Correlation analysis showed significant association between age and overall score of NEI-VFQ-25 in AMD patients $(r=-0.475, P=0.001)$, and not with POAG patients $(r=-0.112, P=0.437$; Table 3$)$. When the subgroups were evaluated in patients with AMD, significant correlation was detected between age and all

Table 2 Average subgroup and overall scores of NEI-VFQ-25 test of the POAG and AMD groups

\begin{tabular}{lccc}
\hline & $P O A G \mathrm{n}=43$ & $A M D \mathrm{n}=49$ & $\mathrm{P}$ \\
\hline General health & $63.95 \pm 12.56$ & $65.82 \pm 12.17$ & 0.473 \\
General vision & $60.47 \pm 12.48$ & $60.71 \pm 16.92$ & 0.936 \\
Ocular pain & $84.89 \pm 12.06$ & $99.23 \pm 3.02$ & $0.001^{*}$ \\
Near activities & $89.35 \pm 13.41$ & $72.43 \pm 16.03$ & $0.001^{*}$ \\
Distance activities & $89.24 \pm 10.40$ & $79.90 \pm 17.24$ & $0.002^{*}$ \\
Vision-specific social functioning & $92.59 \pm 8.76$ & $84.82 \pm 13.62$ & $0.002^{*}$ \\
Vision-specific mental health & $92.44 \pm 6.28$ & $91.19 \pm 5.40$ & 0.312 \\
Vision-specific role difficulties & $93.90 \pm 7.89$ & $92.22 \pm 4.86$ & 0.217 \\
Vision-specific dependency & $96.31 \pm 6.58$ & $90.43 \pm 7.21$ & $0.001^{*}$ \\
Color vision & $95.93 \pm 9.34$ & $100.0 \pm 0.0$ & $0.007^{*}$ \\
Peripheral vision & $91.86 \pm 13.05$ & $100.0 \pm 0.0$ & $0.001^{*}$ \\
Overall score & $86.44 \pm 6.96$ & $84.66 \pm 7.56$ & 0.244 \\
\hline
\end{tabular}

Abbreviations: AMD, age-related macular degeneration; POAG, primary open-angle glaucoma.

Data are expressed as mean \pm SD.

${ }^{*} P<0.05$.

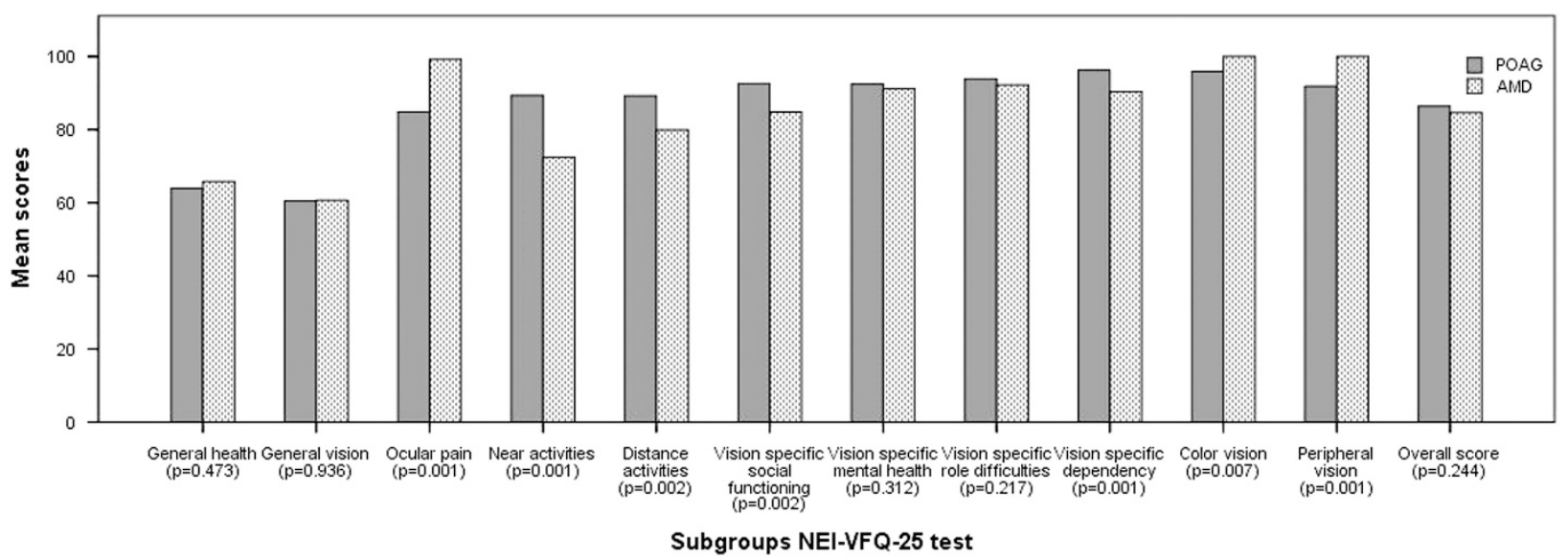

Figure 2 Distribution of mean subgroup and overall scores of NEI-VFQ-25 test in POAG and AMD patients. AMD, age-related macular degeneration; POAG, primary open-angle glaucoma. 
Table 3 Correlation between age and NEI-VFQ-25 scores in patients with POAG and AMD

\begin{tabular}{|c|c|c|c|c|}
\hline & \multicolumn{4}{|c|}{ Age } \\
\hline & \multicolumn{2}{|c|}{$P O A G(\mathrm{n}=43)$} & \multicolumn{2}{|c|}{$A M D(\mathrm{n}=49)$} \\
\hline & $\mathrm{r}$ & $\mathrm{P}$ & $\mathrm{r}$ & $\mathrm{P}$ \\
\hline General health & -0.240 & 0.121 & -0.513 & $<0.001^{*}$ \\
\hline General vision & 0.237 & 0.127 & -0.233 & 0.108 \\
\hline Ocular pain & 0.190 & 0.222 & -0.165 & 0.258 \\
\hline Near activities & -0.075 & 0.632 & -0.522 & $<0.001^{*}$ \\
\hline Distance activities & -0.291 & 0.059 & -0.487 & $<0.001^{*}$ \\
\hline Vision-specific social functioning & -0.372 & $0.014^{*}$ & -0.344 & $0.016^{*}$ \\
\hline Vision-specific mental health & -0.071 & 0.650 & -0.396 & $0.005^{*}$ \\
\hline Vision-specific role difficulties & -0.282 & 0.067 & -0.321 & $0.025^{*}$ \\
\hline Vision-specific dependency & -0.152 & 0.331 & -0.429 & $0.002^{*}$ \\
\hline Color vision & 0.129 & 0.411 & 1.000 & 1.000 \\
\hline Peripheral vision & -0.137 & 0.380 & 1.000 & 1.000 \\
\hline Overall score & -0.122 & 0.437 & -0.475 & $0.001^{*}$ \\
\hline
\end{tabular}

Abbreviations: AMD, age-related macular degeneration; POAG, primary open-angle glaucoma.

${ }^{*} P<0.05$.

subgroups apart from general vision, ocular pain, color vision, and peripheral vision, whereas only social function was correlated with age in patients with POAG.

NEI-VFQ-25 parameters in both groups were not significantly different with respect to gender. Statistically significant correlation was detected between all visual field parameters and overall score of NEI-VFQ-25 questionnaire in both groups (Table 4). Statistically significant correlation was found between the subgroups of near activities, peripheral vision, and color vision, and 24-2 MD, 24-2 PSD, 10-2 MD, 10-2 PSD, and central field defect for POAG group. In addition, statistically significant correlation was found between subgroups of distance activities and 24-2 MD, 24-2 PSD, 10-2 MD, and 10-2 PSD for POAG group. Statistically significant correlation was found between the subgroups of general health, near activities, distance activities, and mental health, and 24-2 MD, 24-2 PSD, 10-2 MD, 10-2 PSD, and central field defect for AMD group. Significant correlation was identified between subgroups of general vision and vision-specific social functioning, and 24-2 MD, 24-2 PSD, 10-2 MD and 10-2 PSD for AMD group (Table 4).

Strong positive correlation was determined between BCVA and overall score of NEI-VFQ-25 questionnaire in POAG $(r=0.604, P=0.001)$ and AMD $(r=0.916, P=0.001)$ groups (Table 5). Statistically significant correlation was found in all parameters except for general health and ocular pain in POAG group. Strongest correlation in AMD group was observed with the overall score $(r=0.906, P=0.001)$ and weakest correlation was with ocular pain $(r=0.64, P=0.01)$. Statistically significant correlation was identified between CS and overall score of NEI-VFQ-25 questionnaire in POAG and AMD groups, at all spatial frequencies. Statistically significant correlation was found between all subgroups except for general health and vision-specific role difficulties, and CS at all spatial frequencies in POAG group. In AMD group, correlation was identified between CS values and all NEIVFQ-25 questionnaire subgroups except for ocular pain at all spatial frequencies (Table 5).

\section{Discussion}

Various clinical parameters such as intraocular pressure, visual field test results, fundus fluorescein angiography, and optical coherence tomography images are important for ophthalmologists in the surveillance of glaucomatous optic neuropathy and AMD. The effects of these diseases on daily activities and the risk of losing useful vision in the future, however, constitute the major concerns for the patients. Recent research is, therefore, directed to investigate QoL in patients with glaucoma and AMD. QoL in patients with glaucoma and AMD were shown to be impaired, with multiple daily activities being more difficult to perform compared with normal individuals. ${ }^{4-8,18,28-30}$

Several studies have investigated vision-related QoL in patients with glaucoma and AMD. ${ }^{7,14-21,31-36}$ They revealed that total scores of general sighted population was significantly higher compared with AMD or POAG patients. ${ }^{13,14,17,21}$ Mangione et al ${ }^{13}$ observed that overall scores were lower for the patients with various chronic eye diseases including AMD $(67.1 \pm 13.4)$ and POAG $(80.2 \pm 12.5)$ compared with a reference sample of participants with no evidence of underlying eye disease $(88.1 \pm 15.3)$. This suggests that NEI-VFQ-25 is sensitive to different levels of visual function in the better eye of patients with AMD and POAG. 
Table 4 Correlation analysis of NEI-VFQ-25 scores and visual field parameters in cases with POAG and AMD

\begin{tabular}{|c|c|c|c|c|c|c|c|c|c|c|}
\hline & \multicolumn{2}{|c|}{ 24-2MD } & \multicolumn{2}{|c|}{ 24-2 PSD } & \multicolumn{2}{|c|}{ Central visual field defect } & \multicolumn{2}{|c|}{$10-2 M D$} & \multicolumn{2}{|c|}{ 10-2 PSD } \\
\hline & $P O A G$ & $A M D$ & $P O A G$ & $A M D$ & $P O A G$ & $A M D$ & $P O A G$ & $A M D$ & $P O A G$ & $A M D$ \\
\hline \multicolumn{11}{|c|}{ General health } \\
\hline$r$ & 0.201 & 0.432 & -0.151 & -0.489 & 0.060 & -0.385 & -0.022 & 0.308 & 0.005 & -0.397 \\
\hline$P$ & 0.197 & $0.002^{*}$ & 0.335 & $<0.001^{*}$ & 0.703 & $0.006^{*}$ & 0.888 & $0.031^{*}$ & 0.974 & $0.005^{*}$ \\
\hline \multicolumn{11}{|c|}{ General vision } \\
\hline$r$ & 0.155 & 0.382 & -0.263 & -0.419 & 0.138 & -0.235 & -0.093 & 0.385 & 0.094 & -0.479 \\
\hline$P$ & 0.320 & $0.007^{*}$ & 0.089 & $0.003^{*}$ & 0.379 & 0.105 & 0.552 & $0.006^{*}$ & 0.549 & $0.001^{*}$ \\
\hline \multicolumn{11}{|c|}{ Ocular pain } \\
\hline$r$ & 0.161 & 0.015 & -0.204 & -0.073 & -0.036 & 0.018 & 0.178 & 0.017 & -0.001 & -0.256 \\
\hline$P$ & 0.303 & 0.92 & 0.189 & 0.62 & 0.821 & 0.902 & 0.255 & 0.908 & 0.993 & 0.076 \\
\hline \multicolumn{11}{|c|}{ Near activities } \\
\hline$r$ & 0.615 & 0.529 & -0.417 & -0.552 & -0.813 & -0.344 & 0.578 & 0.476 & -0.771 & -0.502 \\
\hline$P$ & $<0.001^{*}$ & $<0.001^{*}$ & $0.004^{*}$ & $<0.001^{*}$ & $<0.001^{*}$ & $0.016^{*}$ & $<0.001^{*}$ & $<0.001^{*}$ & $<0.001^{*}$ & $<0.001^{*}$ \\
\hline \multicolumn{11}{|c|}{ Distance activities } \\
\hline$r$ & 0.339 & 0.401 & -0.127 & -0.428 & -0.232 & -0.303 & 0.302 & 0.286 & -0.386 & -0.361 \\
\hline$P$ & $0.026^{*}$ & $0.004^{*}$ & $0.048^{*}$ & $0.002^{*}$ & 0.135 & $0.035^{*}$ & $0.049^{*}$ & 0.047 & $0.011^{*}$ & $0.011^{*}$ \\
\hline \multicolumn{11}{|c|}{ Vision-specific social functioning } \\
\hline$r$ & 0.282 & 0.296 & -0.118 & -0.348 & -0.161 & -0.202 & 0.146 & 0.329 & -0.280 & -0.467 \\
\hline$P$ & 0.067 & $0.039^{*}$ & 0.452 & $0.014^{*}$ & 0.303 & 0.164 & 0.349 & $0.021^{*}$ & 0.069 & $0.001^{*}$ \\
\hline \multicolumn{11}{|c|}{ Vision-specific mental health } \\
\hline$r$ & 0.071 & 0.516 & -0.109 & -0.492 & 0.058 & -0.329 & 0.038 & 0.347 & -0.075 & -0.491 \\
\hline$P$ & 0.653 & $<0.001^{*}$ & 0.486 & $0.000^{*}$ & 0.712 & $0.021^{*}$ & 0.810 & $0.015^{*}$ & 0.631 & $<0.001^{*}$ \\
\hline \multicolumn{11}{|c|}{ Vision-specific role difficulties } \\
\hline$r$ & 0.062 & 0.218 & 0.027 & -0.221 & 0.068 & -0.142 & 0.039 & 0.12 & -0.066 & -0.170 \\
\hline$P$ & 0.691 & 0.133 & 0.863 & 0.127 & 0.665 & 0329 & 0.806 & 0.412 & 0.675 & 0.242 \\
\hline \multicolumn{11}{|c|}{ Vision-specific dependency } \\
\hline$r$ & 0.248 & 0.377 & -0.122 & -0.425 & -0.195 & -0.268 & 0.203 & 0.374 & -0.293 & -0.482 \\
\hline$P$ & 0.109 & $0.008^{*}$ & 0.434 & $0.002^{*}$ & 0.209 & 0.063 & 0.191 & $0.008^{*}$ & 0.056 & $<0.001^{*}$ \\
\hline \multicolumn{11}{|c|}{ Color vision } \\
\hline$r$ & 0.545 & 1.000 & -0.468 & 1.000 & -0.621 & 1.000 & 0.559 & 1.000 & -0.641 & 1.000 \\
\hline$P$ & $<0.001^{*}$ & 1.000 & $0.002^{*}$ & 1.000 & $<0.001^{*}$ & 1.000 & $<0.001^{*}$ & 1.000 & $<0.001^{*}$ & 1.000 \\
\hline \multicolumn{11}{|c|}{ Peripheral vision } \\
\hline$r$ & 0.588 & 1.000 & -0.392 & 1.000 & -0.535 & 1.000 & 0.449 & 1.000 & -0.556 & 1.000 \\
\hline$P$ & $<0.001^{*}$ & 1.000 & $0.009^{*}$ & 1.000 & $<0.001^{*}$ & 1.000 & $0.003^{*}$ & 1.000 & $<0.001^{*}$ & 1.000 \\
\hline \multicolumn{11}{|c|}{ Overall score } \\
\hline$r$ & 0.470 & 0.468 & -0.344 & -0.502 & -0.337 & -0.361 & 0.337 & 0.364 & -0.414 & -0.468 \\
\hline$P$ & $0.001^{*}$ & $0.001^{*}$ & $0.024^{*}$ & $0.000^{*}$ & $0.027^{*}$ & $0.011^{*}$ & $0.027^{*}$ & $0.010^{*}$ & $0.006^{*}$ & $0.001^{*}$ \\
\hline
\end{tabular}

Abbreviations: AMD, age-related macular degeneration; POAG, primary open-angle glaucoma. ${ }^{*} P<0.05$.

None of the previous studies have compared QoL in AMD and POAG simultaneously among patients with similar visual acuity. The study by Evans et al ${ }^{4}$ reported the results of a systematic literature search to identify publications that investigated QoL in patients with glaucoma and AMD. The patient groups were not age, gender, or visual acuity matched. They used NEI-VFQ-25 test; general health and general vision subgroups were more commonly affected in patients with glaucoma, whereas driving, general health, general vision, and near vision were more commonly affected in patients with AMD. In contrast to our study, overall QoL was more affected in glaucoma. Although valuable data were presented in the study of Evans et al, ${ }^{4}$ nonuniform nature 
Table 5 Correlation between NEI-VFQ-25 scores and visual acuity/contrast sensitivity in patients with POAG and AMD

\begin{tabular}{|c|c|c|c|c|c|c|c|c|c|c|}
\hline & \multicolumn{2}{|c|}{ Visual acuity } & \multicolumn{2}{|c|}{ Contrast A } & \multicolumn{2}{|c|}{ Contrast B } & \multicolumn{2}{|c|}{ Contrast C } & \multicolumn{2}{|c|}{ Contrast D } \\
\hline & POAG & $A M D$ & $P O A G$ & $A M D$ & $P O A G$ & $A M D$ & $P O A G$ & $A M D$ & $P O A G$ & $A M D$ \\
\hline \multicolumn{11}{|c|}{ General health } \\
\hline$r$ & 0.202 & 0.402 & 0.179 & 0.401 & 0.179 & 0.363 & 0.179 & 0.468 & 0.171 & 0.570 \\
\hline$P$ & 0.193 & $0.004^{*}$ & 0.250 & $0.004^{*}$ & 0.250 & $0.010^{*}$ & 0.250 & $0.001^{*}$ & 0.272 & $<0.001^{*}$ \\
\hline \multicolumn{11}{|c|}{ General vision } \\
\hline$r$ & 0.400 & 0.811 & 0.461 & 0.917 & 0.461 & 0.873 & 0.461 & 0.477 & 0.473 & 0.582 \\
\hline$P$ & $0.008^{*}$ & $<0.001^{*}$ & $0.002^{*}$ & $<0.001^{*}$ & $0.002^{*}$ & $<0.001^{*}$ & $0.002^{*}$ & $0.001^{*}$ & $0.001^{*}$ & $<0.001^{*}$ \\
\hline \multicolumn{11}{|c|}{ Ocular pain } \\
\hline$r$ & 0.206 & 0.364 & 0.338 & 0.264 & 0.338 & 0.243 & 0.338 & 0.335 & 0.339 & 0.391 \\
\hline$P$ & 0.185 & $0.010^{*}$ & $0.027^{*}$ & 0.067 & $0.027^{*}$ & 0.092 & $0.027^{*}$ & $0.019^{*}$ & $0.026^{*}$ & $0.005^{*}$ \\
\hline \multicolumn{11}{|c|}{ Near activities } \\
\hline$r$ & 0.415 & 0.879 & 0.589 & 0.813 & 0.589 & 0.761 & 0.589 & 0.553 & 0.589 & 0.588 \\
\hline$P$ & $0.006^{*}$ & $<0.001^{*}$ & $<0.001^{*}$ & $<0.001^{*}$ & $<0.001^{*}$ & $<0.001^{*}$ & $<0.001^{*}$ & $<0.001^{*}$ & $<0.001^{*}$ & $<0.001^{*}$ \\
\hline \multicolumn{11}{|c|}{ Distance activities } \\
\hline$r$ & 0.624 & 0.888 & 0.571 & 0.847 & 0.571 & 0.792 & 0.571 & 0.602 & 0.574 & 0.675 \\
\hline$P$ & $0.001^{*}$ & $<0.001^{*}$ & $<0.001^{*}$ & $<0.001^{*}$ & $<0.001^{*}$ & $<0.001^{*}$ & $<0.001^{*}$ & $<0.001^{*}$ & $<0.001^{*}$ & $<0.001^{*}$ \\
\hline \multicolumn{11}{|c|}{ Vision-specific social functioning } \\
\hline$r$ & 0.589 & 0.838 & 0.466 & 0.819 & 0.466 & 0.766 & 0.466 & 0.531 & 0.468 & 0.559 \\
\hline$P$ & $0.001^{*}$ & $<0.001^{*}$ & $0.002^{*}$ & $<0.001^{*}$ & $0.002^{*}$ & $<0.001^{*}$ & $0.002^{*}$ & $<0.001^{*}$ & $0.002^{*}$ & $<0.001^{*}$ \\
\hline \multicolumn{11}{|c|}{ Vision-specific mental health } \\
\hline$r$ & 0.540 & 0.894 & 0.374 & 0.828 & 0.374 & 0.791 & 0.374 & 0.477 & 0.383 & 0.501 \\
\hline$P$ & $0.001^{*}$ & $<0.001^{*}$ & $0.013^{*}$ & $<0.001^{*}$ & $0.013^{*}$ & $<0.001^{*}$ & $0.013^{*}$ & $0.001^{*}$ & $0.011^{*}$ & $<0.001^{*}$ \\
\hline \multicolumn{11}{|c|}{ Vision-specific role difficulties } \\
\hline$r$ & 0.496 & 0.724 & 0.286 & 0.529 & 0.286 & 0.491 & 0.286 & 0.444 & 0.288 & 0.385 \\
\hline$P$ & $0.001^{*}$ & $<0.001^{*}$ & 0.063 & $<0.001^{*}$ & 0.063 & $<0.001^{*}$ & 0.063 & $0.001^{*}$ & 0.061 & $0.006^{*}$ \\
\hline \multicolumn{11}{|c|}{ Vision-specific dependency } \\
\hline$r$ & 0.442 & 0.883 & 0.327 & 0.817 & 0.327 & 0.764 & 0.327 & 0.546 & 0.326 & 0.559 \\
\hline$P$ & $0.001^{*}$ & $<0.001^{*}$ & $0.032^{*}$ & $<0.001^{*}$ & $0.032^{*}$ & $<0.001^{*}$ & $0.032^{*}$ & $<0.001^{*}$ & $0.033^{*}$ & $<0.001^{*}$ \\
\hline \multicolumn{11}{|c|}{ Color vision } \\
\hline$r$ & 0.281 & 1.000 & 0.443 & 1.000 & 0.443 & 1.000 & 0.443 & 1.000 & 0.437 & 1.000 \\
\hline$P$ & $0.044^{*}$ & 1.000 & $0.003^{*}$ & 1.000 & $0.003^{*}$ & 1.000 & $0.003^{*}$ & 1.000 & $0.003^{*}$ & 1.000 \\
\hline \multicolumn{11}{|c|}{ Peripheral vision } \\
\hline$r$ & 0.426 & 1.000 & 0,626 & 1.000 & 0.626 & 1.000 & 0.626 & 1.000 & 0.626 & 1.000 \\
\hline$P$ & $0.004^{*}$ & 1.000 & $<0.001^{*}$ & 1.000 & $<0.001^{*}$ & 1.000 & $<0.001^{*}$ & 1.000 & $<0.001^{*}$ & 1.000 \\
\hline \multicolumn{11}{|c|}{ Overall score } \\
\hline$r$ & 0.604 & 0.916 & 0.640 & 0.877 & 0.640 & 0.821 & 0.640 & 0.599 & 0.642 & 0.652 \\
\hline$P$ & $0.001^{*}$ & $<0.001^{*}$ & $0.001^{*}$ & $0.001^{*}$ & $0.001^{*}$ & $0.001^{*}$ & $0.001^{*}$ & $0.001^{*}$ & $0.001^{*}$ & $0.001^{*}$ \\
\hline
\end{tabular}

Abbreviations: AMD, age-related macular degeneration; POAG, primary open-angle glaucoma. ${ }^{*} \mathrm{P}<0.05$.

of study population should call for careful assessment of those results. Suzukamo et al, ${ }^{17}$ who used NEI-VFQ-25 test in their study, found that QoL in patients with AMD were affected more compared with those with glaucoma. They reported that general health, general vision, and mind health were substantially affected in 69 patients with glaucoma, whereas all parameters other than peripheral vision, color vision, and ocular pain were substantially affected in patients with AMD. However, age and visual acuity of patients in the mentioned study were not similar.

In the current study, QoL of 43 patients with POAG and 49 age-, gender-, and visual acuity-matched patients with early-stage AMD were analyzed. Overall QoL scores of patients with POAG and AMD $(86.44 \pm 6.96$ and 
$84.66 \pm 7.56$, respectively) were similar. Among 11 health domains, general vision and general health parameters were affected most both in patients with POAG and AMD. Peripheral vision, color vision, and ocular pain were affected more in patients with POAG compared with patients with AMD, whereas near activity, distance activity, social function, and dependency were affected more in AMD patients. The study groups were composed of mainly early POAG and early AMD patients with average BCVA values (Snellen chart) of $0.66 \pm 0.12$ and $0.60 \pm 0.18$, respectively. All parameters other than general health and ocular pain were significantly correlated with BCVA in patients with POAG. Failure of pain score to show correlation with visual acuity may be attributed to the fact that all glaucoma patients used topical anti-glaucomatous drops, whereas no topical medication was used in the AMD group. Gutierrez et al ${ }^{37}$ reported a similar correlation between BCVA and NEIVFQ-25 parameters in patients with POAG. Significant correlation was also found between BCVA and all parameters of NEI-VFQ-25 other than color vision and peripheral vision in our patients with AMD. Strongest correlation was observed with overall score and worst correlation was with ocular pain. Similar findings were reported in the literature. ${ }^{30,38-40}$

In the current study, results of 24-2 SITA and 10-2 SITA visual field tests were used to provide an objective measure to evaluate the impact of field changes on QoL. MD values of Humphrey 24-2 SITA visual field tests were found to be significantly lower in patients with POAG than those with AMD. MD values of central 10-2 SITA standard tests were significantly lower in patients with AMD than those with POAG. These findings are to be expected, given the nature of both diseases; glaucoma typically results in peripheral visual field loss and AMD causes visual loss owing to involvement of central retina.

Association between NEI-VFQ results and severity of glaucoma was investigated in several studies using different visual field tests (eg, Esterman binocular visual field test) and grading systems (eg, Hodapp-AndersonParrish score, the Collaborative Initial Glaucoma Treatment Study score, and the Advanced Glaucoma Intervention Study score). Parrish et $a^{31}$ reported that the following NEI-VFQ subscales were significantly correlated with Esterman binocular visual field impairment: general vision $(r=-0.47)$, near vision $(r=-0.52)$, distance vision $(r=-0.56)$, social functioning $(r=-0.53)$, mental health $(r=-0.47)$, role difficulties $(r=-0.49)$, dependency $(r=-0.59)$, driving $(r=-0.52)$, color vision $(r=-0.47)$, and peripheral vision $(r=-0.51)$. Wren et $a l^{32}$ found significant correlations between MD and most NEI-VFQ scores. Suzukamo et al ${ }^{17}$ identified significant correlation between MD and NEI-VFQ subscales including peripheral vision, distance vision, driving, and dependency in both the better and worse eyes of patients with glaucoma. Jampel et al ${ }^{33}$ noted weak correlation between the overall NEI-VFQ-25 score and MD in the better eye $(r=0.32, P$-value $<0.001)$. Labiris et $a l^{34}$ documented a significant correlation between average MD $(-3.2 \mathrm{~dB})$ in the better eyes of the patients with glaucoma and most NEI-VFQ subscales including color vision, general vision, near vision, driving, social functioning, and dependency. Peters et $a l^{20}$ found a statistically significant correlation between vision-related QoL measured by the NEI-VFQ-25 and visual field loss in the better eye. In the present study, significant correlation was found between MD values of 24-2 standard visual field and near activity, distance activity, color vision, and peripheral vision. Strongest correlation was with near activity $(r=0.615)$ and weakest correlation was with distance activity $(r=0.339)$ in the better eye.

In our study, 10-2 visual field test was performed for detailed examination of central visual functions. The results of 10-2 visual field test (both MD and PSD) were correlated with QoL in POAG. Highest correlation was observed with near activity (MD $r=0.578$, PSD $r=-0.771$ ). The presence of high correlation with near vision in patients with early glaucoma is intriguing as central vision is expected to be affected less and at a later stage. Sawada et $a l^{35}$ evaluated the correlation between Japanese version of vision-specific QoL and visual function in patients with glaucoma. In addition to visual acuity, QoL was highly correlated with the central 10-2 MD in the better eye. Furthermore, they reported that manifestation of early visual field defect simultaneously led to decline in the vision-specific QoL. ${ }^{35}$

In the current study, central extension of field defects in 24-2 visual field test was used as another method for assessment of central visual function. There was statistically significant relationship between subgroups of near activity, color vision, and peripheral vision and defects extending to central $10^{\circ}$ of the visual field in POAG group. Highest correlation was observed for near vision domain $(r=-0.813)$. Similarly, McKean-Cowdin et $a l^{36}$ observed decreased NEI-VFQ scores of 230 patients with POAG in the presence of damage extending to the central visual field.

In patients with AMD, strongest and weakest correlations were observed with near activity $(r=0.529$ and $r=0.552)$ and social function $(r=0.296$ and $r=0.348)$ for MD and PSD values of 24-2 standard visual field, respectively. 10-2 MD values and visual field defects extending to central $10^{\circ}$ had strongest and weakest correlations with near activity $(r=0.476$ and $r=-0.344)$ and distance activity ( $r=0.286$ and $r=-0.303)$, respectively. Correlation with visual field defects extending to central $10^{\circ}$, however, was not as strong as the correlation observed in POAG. The results of the current 
study pointed out to the possibility of using visual field parameters as a tool for evaluation of QoL in patients with early-stage AMD. Further, comprehensive studies involving large study populations are needed to verify these findings.

In the current study, CS values were found to be lower than the normative data values at all spatial frequencies in both glaucoma and AMD patients. It is known that changes in CS occur early in the course of glaucoma, however, visual acuity remains unaffected until the advanced stages of the disease. ${ }^{41,42}$ Although there is a significant correlation between CS and visual acuity in patients with AMD, they do not always progress at a similar rate. ${ }^{43}$ The correlation between CS values at all spatial frequencies in POAG patients and NEI-VFQ-25 parameters was highest with the general score $(r=0.640)$ and lowest with ocular pain $(r=0.338)$. Hawkins et $a l^{44}$ described statistically significant correlation between CS values, visual acuity and MD values of 24-2 visual field ( $r=-0.370$ and $r=0.57$, respectively). Richman et $a l^{45}$ found that CS and binocular visual acuity were the best predictors of the ability of patients with glaucoma to perform daily activities. They suggested that CS should be included in the NEI-VFQ to allow a more accurate reflection of function. Furthermore, Richman et al ${ }^{45}$ concluded that CS could be a better tool compared with visual acuity in understanding the functional ability of patients with glaucoma. Our results support their findings. CS may be an important way to evaluate QoL in patients with early glaucomatous changes.

CS provides valuable additional information in patients with AMD. ${ }^{46-48}$ CS scores were found to be significantly lower in patients with both early and late AMD compared with controls. Bansback et al ${ }^{47}$ studied CS in a large group of both dry and wet AMD patients, and utilized visual function index-14, health utilities mark 3 , and time tradeoff questionnaires for the evaluation of QoL. They found high correlation $(r=0.73)$ between VF-14 and CS. ${ }^{47}$ They reported that CS remained a statistically significant predictor of all outcome measures even when visual acuity was included, and concluded that the measurement of CS appeared to be better related to a person's QoL and health utility. ${ }^{47}$ Rubin et al ${ }^{48}$ found an independent contribution of CS to several domains of the Activities of Daily Vision Scale, a separate measure of visual function. In our AMD group, moderate to high correlation was found between CS values and all parameters other than ocular pain, color vision, and peripheral vision at spatial frequencies of 3 and 6 c.p.d. For spatial frequencies of 12 and 18 c.p.d., statistically significant correlation was found between CS values and all parameters other than color vision and peripheral vision. In contrast to our AMD group, the patients in the study by Bansback et $a l^{47}$ had worse average BCVA, and both Bansback ${ }^{47}$ and Rubin et al ${ }^{48}$ used different measures for the evaluation of both QoL and CS. Despite all these differences, the results of both their studies and the current study indicate that CS can be a significant tool to evaluate patients in early and late stages of AMD.

Unlike most of the previous reports, our sample contained patients with early stages of glaucoma and AMD. In patients with advanced POAG and AMD, the reported range of overall NEI-VFQ-25 scores (from $69.8 \pm 1.9$ to $78.3 \pm 14.9$ and from $51 \pm 2$ to $67.8 \pm 18$, respectively) were lower than the present study $(86.44 \pm 6.96$ and $84.66 \pm 7.56$, respectively). 4,14,17,18,21,49 Wolfram et al ${ }^{14}$ demonstrated that advanced POAG $(71.5 \pm 19.3)$ was significantly associated with low NEI-VFQ-25 scores compared with early $(90.7 \pm 8.1)$ and moderate POAG $(86.1 \pm 8.7)$. Similarly, patients with advanced or late-stage AMD experience a major reduction in QoL. ${ }^{40}$ A recent population-based study conducted in adult Latino population revealed overall NEIVFQ-25 scores of 59.5 (95\% CI, 50.8-68.1) for those with latestage AMD and 79.4 (95\% CI, 72.5-86.1) for those with early-stage AMD. ${ }^{21}$

The current study showed that patients with similar visual acuity experience similar overall impairment in QoL whether they had early-stage glaucoma or AMD, despite the fact that they essentially affect visual function through different mechanisms. They both experience loss of QoL mainly in subgroups of general health and general vision. Glaucoma patients describe more difficulty with peripheral vision and ocular pain, whereas AMD patients complain more about near and distance vision, and dependency items. CS loss and perimetric defects are noted in early stages of both diseases. Hence, analysis of CS and visual field defects might provide efficient means of evaluation of QoL, along with regular vision-specific QoL analysis questionnaires, in POAG and AMD patients.

\section{Summary}

\section{What was known before}

- Impairment of quality of life in patients with glaucoma and age-related macular degeneration was reported by previous studies, in which patient groups were not age, gender, or visual acuity matched.

- National Eye Institute Visual Function Questionnaire is an instrument that can be used to assess vision-specific quality of life.

What this study adds

- This study demonstrated that patients with similar visual acuity who had early-stage glaucoma or age-related macular degeneration experience similar overall impairment in quality of life. 


\section{Conflict of interest}

The authors declare no conflict of interest.

\section{References}

1 Quigley HA, Broman AT. The number of people with glaucoma worldwide in 2010 and 2020. Br J Ophthalmol 2006; 90: 262-267.

2 Vingerling JR, Dielemans I, Hofman A, Grobbee DE, Hijmering M, Kramer CF et al. The prevalence of age-related maculopathy in the Rotterdam study. Ophthalmology 1995; 102: 205-210.

3 Sahel JA, Bandello F, Augustin A, Maurel F, Negrini C, Berdeaux GH. Health-related quality of life and utility in patients with age-related macular degeneration. Arch Ophthalmol 2007; 125: 945-951.

4 Evans K, Law SK, Walt J, Buchholz P, Hansen J. The quality of life impact of peripheral versus central vision loss with a focus on glaucoma versus age-related macular degeneration. Clin Ophthalmol 2009; 3: 433-445.

5 Congdon N, O'Colmain B, Klaver CC, Klein R, Muñoz B, Friedman DS et al. Causes and prevalence of visual impairment among adults in the United States. Arch Ophthalmol 2004; 122: 477-485.

6 Scott JU, Smiddy WE, Schiffman J, Feuer WJ, Pappas CJ. Quality of life of low-vision patients and the impact of low-vision services. Am J Ophthalmol 1999; 128: 54-62.

7 Scilley K, Jackson GR, Artur V, Cideciyan AV, Maguire MG, Jacobson SG et al. Early age-related maculopathy and selfreported visual difficulty in daily life. Ophthalmology 2002; 109: 1235-1242.

8 Spaeth G, Walt J. Evaluation of quality of life for patients with glaucoma. Am J Ophthalmol 2006; 141(1 Suppl): S3-S14.

9 Thayaparan AJ, Mahdi E. The patients satisfaction questionnaire short form (PSQ-18) as an adaptable, reliable, and validated tool for use in various settings. Med Educ Online 2013; 18: 21747.

10 McHorney CA, Ware J Jr. Construction and validation of an alternate form general mental health scale for the Medical Outcomes Study Short-Form 36-list-item Health Survey. Med Care 1995; 33: 15-28.

11 Ware Jr J, Kosinski M, Keller SD. A 12-list-item Short-Form Health Survey: construction of scales and preliminary tests of reliability and validity. Med Care 1996; 34: 220-233.

12 Hays RD, Sherbourne CD, Mazel RM. The RAND 36-listitem Health Survey 1.0. Health Econ 1993; 2: 217-227.

13 Mangione CM, Lee PP, Pitts J, Gutierrez P, Berry S, Hays RD. Psychometric properties of the National Eye Institute Visual Function Questionnaire (NEI-VFQ). NEI-VFQ Field Test Investigators. Arch Ophthalmol 1998; 116: 1496-1504.

14 Wolfram C, Lorenz K, Breitscheidel L, Verboven Y, Pfeiffer N. Health- and vision-related quality of life in patients with ocular hypertension or primary open-angle glaucoma. Ophthalmologica 2013; 229: 227-234.

15 Parrish RK 2nd. Visual impairment, visual functioning, and quality of life assessments in patients with glaucoma. Trans Am Ophthalmol Soc 1996; 94: 919-1028.

16 Ringsdorf L, McGwin Jr G, Owsley C. Visual field defects and vision specific health related quality of life in African Americans and whites with glaucoma. J Glaucoma 2006; 15: 414-418.
17 Suzukamo Y, Oshika T, Yuzawa M, Takuda Y, Tomidokoro A, Oki K et al. Psychometric properties of the 25-item National Eye Institute Visual Function Questionnaire (NEI VFQ-25), Japanese version. Health Qual Life Outcomes 2005; 3: 65.

18 Berdeaux GH, Nordmann JP, Colin E, Arnould B. Visionrelated quality of life in patients suffering from age-related macular degeneration. Am J Ophthalmol 2005; 139: 271-279.

19 Hyman LG, Komaroff E, Heijl A, Bengtsson B, Leske MC. Treatment and vision-related quality of life in the early manifest glaucoma trial. Ophthalmology 2005; 112: 1505-1513.

20 Peters D, Heijl A, Brenner L, Bengtsson B. Visual impairment and vision-related quality of life in the Early Manifest Glaucoma Trial after 20 years of follow-up. Acta Ophthalmol 2015; 93: 745-752.

21 Choudhury F, Varma R, Klein R, Gauderman WJ, Azen SP, McKean-Cowdin $\mathrm{R}$ et al. Age-related macular degeneration and quality of life in Latinos: The Los Angeles Latino Eye Study. JAMA Ophthalmol 2016; 134: 683-690.

22 Orta AO, Ozturker ZK, Erkul SO, Bayraktar S, Yilmaz OF. The correlation between glaucomatous visual field loss and vision-related quality of life. J Glaucoma 2015; 24: e121-e127.

23 Mills RP, Budenz DL, Lee PP, Noecker RJ, Siegartel LR, Evans SJ et al. Categorizing the stage of glaucoma from pre-diagnosis to end-stage disease. Am J Ophthalmol 2006; 141: 24-30.

24 Spaeth GL, Shields MB. The stages of glaucoma. Am J Ophthalmol 2006; 141: 147-148.

25 Bird AC, Bressler NM, Bressler SB, Chisholm IH, Coscas G, Davis MD et al. An international classification and grading system for age-related maculopathy and age-related macular degeneration. The International ARM Epidemiological Study Group. Surv Ophthalmol 1995; 39: 367-374.

26 Evans DW. Contrast sensitivity testing experts. Available at: http:/ / www.vectorvision.com/csv1000-contrast-sensitivity (accessed on 10 December 2015).

27 Toprak AB, Eser E, Guler C, Baser FE, Mayali H. Crossvalidation of the Turkish version of the 25-Item National Eye Institute Visual Functioning Questionnaire (NEI-VFQ 25). Ophthalmic Epidemiol 2005; 12: 259-269.

28 Mills RP. Correlation of quality of life with clinical symptoms and signs at the time of glaucoma diagnosis. Trans Am Ophthalmol Soc 1998; 96: 753-812.

29 Ramulu R. Glaucoma and disability: which tasks are affected, and at what stage of disease? Curr Opin Ophthalmol 2009; 20: 92-98.

30 Glen FC, Crabb DP, Garway-Heath DF. The direction of research into visual disability and quality of life in glaucoma. BMC Ophthalmol 2011; 11: 19.

31 Parrish RK 2nd, Gedde SJ, Scott IU, Feuer WJ, Schiffman JC, Mangione CM et al. Visual function and quality of life among patients with glaucoma. Arch Ophthalmol 1997; 115: 1447-1455.

32 Wren PA, Musch DC, Janz NK, Niziol LM, Guire KE, Gillespie BW et al. Contrasting the use of 2 vision-specific quality of life questionnaires in subjects with open-angle glaucoma. J Glaucoma 2009; 18: 403-411.

33 Jampel HD, Schwartz A, Pollack I, Abrams D, Weiss H, Miller R. Glaucoma patients' assessment of their visual function and quality of life. J Glaucoma 2002; 11: 154-163.

34 Labiris G, Katsanos AA, Fanariotis M, Zacharaki F, Chatzoulis D, Kozobolis VP. Vision-specific quality of life in Greek glaucoma patients. J Glaucoma 2010; 19: 39-43.

35 Sawada H, Fukuchi T, Abe H. Evaluation of the relationship between quality of vision and visual function in Japanese glaucoma patients. Clin Ophthalmol 2011; 5: 259-567. 
36 McKean-Cowdin R, Varma R, Wu J, Hays RD, Azen SP. Los Angeles Latino Eye Study Group Severity of visual field loss and health-related quality of life. Am J Ophthalmol 2007; 143: 1013-1023.

37 Gutierrez P, Wilson MR, Johnson C, Gordon M, Cioffi GA, Ritch $\mathrm{R}$ et al. Influence of glaucomatous visual field loss on health-related quality of life. Arch Ophthalmol 1997; 115: 777-784.

38 Clemons TE, Chew EY, Bressler SB, McBee W. Age-Related Eye Disease Study Research Group National Eye Institute Visual Function Questionnaire in the Age-Related Eye Disease Study (AREDS): AREDS Report No. 10. Arch Ophthalmol 2003; 121: 211-217.

39 Mangione CM, Lee PP, Gutierrez PR, Spritzer K, Berry S, Hays RD. Development of the 25-Item National Eye Institute Visual Function Questionnaire. Arch Ophthalmol 2001; 119: 1050-1058.

40 Yuzawa M, Fujita K, Tanaka E, Wang ECY. Assessing quality of life in the treatment of patient with age-related macular degeneration: clinical research findings and recommendations for clinical practice. Clin Ophthalmol 2013; 7: 1325-1332.

41 Korth MJ, Junemann AM, Horn FK, Bergua A, Cursiefen C, Velten I et al. Synopsis of various electrophysiological tests in early glaucoma diagnosis: temporal and spatiotemporal contrast sensitivity, light and color contrast pattern-reversal electroretinogram, blue-yellow VEP. Klin Monbl Augenheilkd 2000; 216: 360-368.

42 Velten IM, Korth M, Horn FK, Budde WM. Temporal contrast sensitivity with peripheral and central stimulation in glaucoma diagnosis. Br J Ophthalmol 1999; 83: 199-205.
43 Faria BM, Duman F, Zheng CX, Waisbourd M, Gupta L, Ali $\mathrm{M}$ et al. Evaluating contrast sensitivity in age-related macular degeneration using a novel computer-based test, The Spaeth/ Richman Contrast Sensitivity Test. Retina 2015; 35: 1465-1473.

44 Hawkins AS, Szlyk JP, Ardickas Z, Alexander KR, Wilensky JT. Comparison of contrast sensitivity, visual acuity, and Humphrey visual field testing in patients with glaucoma. J Glaucoma 2003; 12: 134-138.

45 Richman J, Lorenzana LL, Lankaranian D, Dugar J, Mayer JR, Wizov SS et al. Relationships in glaucoma patients between standard vision tests, quality of life, and ability to perform daily activities. Ophthalmic Epidemiol 2010; 17: 144-151.

46 West SK, Rubin GS, Broman AT, Muñoz B, Bandeen-Roche K, Turano K. How does visual impairment affect performance on tasks of everyday life? The SEE Project. Salisbury Eye Evaluation. Arch Ophthalmol 2002; 120: 774-780.

47 Bansback N, Czoski-Murray C, Carlton J, Lewis G, Hughes L, Espallargues $\mathrm{M}$ et al. Determinants of health related quality of life and health state utility in patient with age related macular degeneration: the association of contrast sensitivity and visual acuity. Qual Life Res 2007; 16: 533-543.

48 Rubin GS, Bandeen-Roche K, Huang GH, Muñoz B, Schein OD, Fried LP et al. The association of multiple visual impairments with self-reported visual disability: SEE project. Invest Ophthalmol Vis Sci 2001; 42: 64-72.

49 Jampel HD. Glaucoma patients' assessment of their visual function and quality of life. Trans Am Ophthalmol Soc 2001; 99: 301-317. 